\begin{abstract}
In this article, we argue that teachers' epistemic cognition, in particular their thinking about epistemic aims and reliable processes for achieving those aims, may impact students' understanding of complex, controversial issues. This is because teachers' epistemic cognition may facilitate or constrain their implementation of instruction aiming to engage students in reasoned argumentation through classroom dialogue. We also suggest that teachers may need to reflect on their own epistemic cognition in the context of dialogue-based instruction in order to calibrate it with the aim of deep understanding and the reliable process of reasoned argumentation, which underlie such instruction. Based on our discussion of relevant theoretical frameworks and related empirical evidence, we identify several promising directions for future theoretical and empirical work in this area. In a unique way, this article brings together theoretical frameworks and bodies of empirical work that hitherto have been discussed separately to provide new insights into the potential relationship between teachers' epistemic cognition and students' understanding.
\end{abstract}

Keywords: Epistemic cognition; classroom dialogue; understanding; reflection; teachers 


\section{Teachers' Epistemic Cognition in the Context of Dialogic Practice: A Question of Calibration?}

\section{INTRODUCTION}

In the 21st century, teaching for deep understanding is an important educational goal, nationally as well as internationally (e.g., CCSSO, 2010; OECD, 2013), and, increasingly, teachers participate in instructional interventions aimed at promoting deep understanding through argumentation and dialogue (Murphy, Firetto, Wei, Li, \& Croninger, 2016; Snow \& Hemphill, in press; Wilkinson \& Son, 2011). The main problem explored in this article concerns the extent to which teachers' thinking about knowledge and the process of knowing, termed epistemic cognition within educational psychology (Greene, Sandoval, \& Bråten, 2016), may impact students' construction of deep understanding by being more or less aligned or calibrated with the aim of deep understanding and the recommended processes to achieve it (i.e., argumentation and dialogue). To address this problem, we bring together several theoretical frameworks and constructs that have hitherto been discussed separately and review bodies of empirical literature pertinent to those frameworks that have previously been reviewed in isolation, thus providing a unique theoretical and empirical platform for addressing our main issue.

Therefore, the purpose of this article is to explore the potential importance of teachers' epistemic cognition for students' understanding of complex, controversial issues and discuss conceptual and empirical work relevant to this relationship. This body of research also has implications for design and evaluation of instructional interventions to promote deep understanding of such issues among students, as well as for teacher professional development 
and teacher education. Therefore, such implications will also be given consideration in this article.

Epistemic cognition concerns how individuals think about what they know, what knowledge is, and how they know what they know (Greene, Sandoval, \& Bråten, 2016; Sandoval, Greene, \& Bråten, 2016). Deep understanding of complex and controversial issues involves processing, representing, and evaluating arguments from multiple information resources (Britt, Richter, \& Rouet, 2014; Goldman et al., 2016; Goldman \& Scardamalia, 2013). That teachers' epistemic cognition may impact students' understanding thus implies that teachers' thinking about knowledge and knowing may facilitate or constrain students' construction of deep understanding through engaging in evidence-based argumentation with multiple sources of information. For teachers, implementing dialogue-based instruction that involves students in the interpersonal process of argumentation can be considered a viable way to promote deep understanding. The expectation (or at least hope) is that participation in discussions to collaboratively construct understanding will provide students with skills that are applicable when they work independently with various information resources (Asterhan \& Schwarz, 2016; Murphy et al., 2016; Wilkinson, Murphy, \& Binici, 2015; Wilkinson \& Son, 2011). Success in this endeavor may depend on the extent to which teachers' own epistemic cognition, in particular their thinking about epistemic aims and reliable processes for achieving those aims (Chinn, Buckland, \& Samarapungavan, 2011; Chinn, Rinehart, \& Buckland, 2014), are aligned with the epistemic aim (i.e., deep understanding) and reliable process (i.e., argumentation) that they try to implement in their classrooms. More specifically, we suggest that less adaptive ${ }^{1}$ epistemic cognition on the part of the teachers may interfere with this implementation and hinder longlasting changes in classroom discourse patterns and, as a result, in students' individual 
understanding. Of note is that lack of calibration between teachers' beliefs and thinking on the one hand, and constructivist teaching practices on the other, may be quite common (for a review, see Windschitl, 2002). As we will address in this article, this also may suggest that there is a need to support the development of epistemic cognition among teachers participating in dialogue-based interventions to promote deep understanding, as well as a need to integrate epistemic cognition into teacher education programs (Duffy, Muis, \& Foy, in press; Greene \& Yu, 2016; Sandoval et al., 2016).

The remainder of this article is divided into six main sections. In the first section, we provide a theoretical background by discussing different frameworks relevant for understanding relationships between deep understanding, argumentation, epistemic cognition, and dialogic practice, as well as the role of teachers' epistemic cognition in students' understanding and reflection as a way of developing more adaptive epistemic cognition among teachers. The overarching issue addressed in this article concerns how teachers' epistemic cognition may facilitate or constrain students' construction of deep understanding through argumentation. Because there is not one single theory or construct that can frame our analysis with respect to this issue, we will draw on several frameworks and constructs to generate a background against which we will review empirical work. By bringing them together, we will also provide a unique configuration of theoretical frameworks and constructs relevant for addressing this issue.

In the second section, we review research investigating the effects of engaging students in argumentation through dialogue-based instruction on deep understanding. In the third, we review empirical work on the potential contributions of teachers' epistemic cognition to teaching practice and student understanding. In the fourth, we describe intervention work aiming to support teachers and student teachers in developing more adaptive epistemic cognition. In the 
fifth, we discuss the need to consider teachers' epistemic cognition when designing and evaluating interventions that engage students in argumentation through dialogue to promote deep understanding, as well as implications for teacher education and teacher professional development. Of note is that the empirical work we review in sections two to five previously has been discussed separately but is brought together for the first time in this article to address the overarching issue of how teachers' epistemic cognition may facilitate or constrain students' construction of deep understanding through argumentation. Our review of research in these sections was driven by the unique configuration of theoretical frameworks and constructs that emerged from our theoretical background analysis and conducted to inform that conceptualization. In a final section, we summarize the main outcome of our conceptual and empirical analysis and provide directions for future research.

\section{THEORETICAL BACKGROUND}

Scholars in 21st century literacy (Bråten \& Braasch, 2017; Britt, Rouet, \& Braasch, 2013; Britt et al., 2014; Goldman et al., 2016; Goldman \& Scardamalia, 2013; Leu, Kinzer, Coiro, Castek, \& Henry, 2013) have conceptualized deep understanding as the building of integrated mental representations from multiple information resources that more often than not present conflicting perspectives on the same issue. According to the documents model framework of Britt and colleagues (Britt et al., 2013, 2014) and the disciplinary literacy framework of Goldman and colleagues (Goldman et al., 2016), understanding in various disciplinary areas (e.g., literature, science, and history) requires that individuals are able to make sense of and evaluate arguments, which involves identifying claims and weighing the relevance, accuracy, and sufficiency of supporting information to reach the most reasonable conclusion (Blair \& Johnson, 1987; Britt et al., 2014; Kuhn \& Crowell, 2011). 
One framework that explicitly connects deep understanding and argumentation is the framework for epistemic cognition proposed by Chinn and colleagues (Chinn et al., 2011, 2014; Chinn \& Rinehart, 2016). In that framework, deep understanding is described as an important epistemic aim, representing an expansion of previous work in epistemic cognition that has focused almost exclusively on cognition pertaining to knowledge and knowing (for review, see Sandoval et al., 2016). Moreover, Chinn et al. (2011) introduced the epistemic cognition component of reliable and unreliable processes, with reasoned argumentation, "in which people carefully consider multiple perspectives and share reasons and evidence about which perspective is best" (Chinn et al., 2014, p. 437), generally considered a reliable process for achieving epistemic aims such as deep understanding. Thus, in a context where the epistemic aim of deep understanding is valued, reasoned argumentation can be considered a reliable interpersonal (i.e., social) process to achieve that aim (Chinn et al., 2011, 2014). Although we focus on the epistemic cognition components of epistemic aims and reliable processes in the present article, we acknowledge that other components of epistemic cognition, such as epistemic ideals, may be of importance. ${ }^{2}$

Translating these ideas into instructional practice highlights the importance of classroom dialogue. According to Walton (1990; Walton \& Macagno, 2007), arguments most often occur in dialogues. However, while the term "dialogue" can indicate that knowledge and understanding are co-constructed through a dynamic and relational process (Wilkinson \& Son, 2011), different forms of dialogues may serve different purposes. Walton (1990; Walton \& Macagno, 2007) proposed a typology of six dialogues, ranging from persuasion dialogues aimed to convince an opponent to eristic dialogues aimed to negotiate a relationship through a fight or quarrel. Following Gregory (2006), who related Walton's work to education, only inquiry dialogue is 
likely to frame and foster the kind of reasoned argumentation that can be considered to reliably produce deep understanding (cf., Asterhan \& Schwarz, 2016; Chinn et al., 2014).

An inquiry dialogue involves a collaborative investigation of an ill-structured or open problem space with the goal of gaining insight into the problem and working towards the most reasonable conclusion (Walton \& Macagno, 2007). In that sense, inquiry dialogue can be described as an ideal form of communication for fostering the norms and standards for reasoned argumentation, such as those used by professionals in academic disciplines. In other words, students engaged in reasoned argumentation for understanding can be seen as critically examining different perspectives and making concessions to reason in a collaborative effort to better understand the issue in question (Asterhan, 2013). Importantly, Gregory (2006) suggested that during classroom discussions, the discourse might shift from inquiry to other dialogue types, depending on the stage of the discussion and the needs of the group. For example, students may ask an authoritative source, such as a teacher, about a specific fact as part of information-seeking dialogue, or engage in persuasion dialogue when a participant tries to persuade another of the merits of a particular position (Gregory, 2006). However, such "licit shifts" (Walton, 1998, p. 176) do not interfere with the overarching norms of inquiry dialogue, given that they are used in service of the larger goal of engaging in argumentation to collectively search for the most reasonable answer (Gregory, 2006).

Of note is that working toward the most reasonable answer or conclusion does not necessarily imply that such a conclusion is reached in every dialogue. Rather, many, if not most, dialogues may result in several reasonable conclusions. Importantly, however, the ideal of striving toward the most reasonable conclusion makes the discussion center on and being controlled by the demands of truth (Gardner, 1996, 2015). Thus, it is the "collective commitment 
to move toward truth" (Gardner, 2015, p. 72) that turns the dialogue into an inquiry and makes participants eliminate less reasonable answers, even if they do not necessarily come to agree on the most reasonable one.

Underlying much psychoeducational work emphasizing the importance of argumentation as a verbal and social activity is the idea that engaging in argumentation will lead to individual intellectual gains and improve students' individual understanding and learning (Astahan \& Schwarz, 2016; Kuhn, 2015; Wilkinson et al., 2015). For example, engaging students in reasoned argumentation through inquiry dialogue as described above may be regarded as a means to improve their ability to make sense of arguments and build integrated understanding of an issue when reading multiple conflicting documents on their own. According to Wilkinson et al. (2015), the theoretical mechanism most commonly used to explain possible individual benefits of engaging in argumentation is derived from Vygotsky's $(1978,1986)$ sociocultural perspective, highlighting such constructs as "language as a tool for thought," "scaffolding," "zone of proximal development," and "internalization." In a Vygotskian view, communicative interaction by means of language is fundamental to the development of higher cognitive processes, which are considered internalized, reconstructed forms of activities initially performed under guidance and in collaboration with others (Bråten, 1991). Accordingly, Sun, Anderson, Lin, and Morris (2015) posited that students who participate in argumentation may come to internalize and appropriate linguistic tools of thought that subsequently can be used to perform collaborative as well as individual academic tasks.

Of note is that efforts to improve individual thinking, understanding, and learning by engaging students in reasoned argumentation embedded within classroom dialogic practice have produced somewhat inconsistent results (Asterhan \& Schwarz, 2016; Kuhn, 2015; Wilkinson et 
al., 2015; Wilkinson \& Son, 2011). While this may be due to individual, contextual, and methodological variation across studies, it is highly conceivable that variation in teachers' implementation of dialogic practice also may come into play. In fact, facilitating classroom dialogues during which students engage in argumentation poses a serious challenge for both new and experienced teachers (Alvermann \& Hayes, 1989; Juzwik, Sherry, Caughlan, Heintz, \& Borsheim-Black, 2012; Nguyen, Anderson, Waggoner, \& Rowel, 2007). This is because, in addition to changes in classroom discourse, changes in beliefs and thinking about understanding and the potential benefits of reasoned argumentation and dialogue may be needed for many teachers, suggesting a link between teachers' cognition about epistemic aims and reliable processes on the one hand and their endorsement and implementation of reasoned argumentation for understanding on the other (Greene \& Yu, 2016; Sandoval et al., 2016). ${ }^{3}$

In Buehl and Fives' (2016; see also, Fives, Barnes, Buehl, Mascadri, \& Ziegler, this issue) framework for teachers' epistemic cognition, teachers' epistemic cognition (i.e., thinking about epistemic aims and reliable processes) for themselves is distinguished from their epistemic cognition (i.e., thinking about epistemic aims and reliable processes) for their students. In this view, teachers' epistemic cognition for themselves influences their epistemic stances to ideas and concepts (e.g., doubting or endorsing them), which teachers tend to rely on in their daily practice and implicitly and explicitly share with their students through their words and actions. In addition, teachers' instructional activities and assessments are guided by the epistemic aims that they hold for their students, as well as by their consideration and evaluation of reliable processes that their students can engage in to achieve those aims (Buehl \& Fives, 2016).

Buehl and Fives' (2016) framework thus implies that teachers' epistemic cognition for themselves may work against their epistemic cognition for their students. For example, teachers may 
hold different epistemic (e.g., certain knowledge) or non-epistemic (e.g., social recognition) aims for themselves than for their students (e.g., deep understanding) and perceive other processes as reliable ways to achieve their own aims (e.g., indiscriminately relying on authority for certain knowledge) than the aims they hold for their students (e.g., reasoned argumentation). Presumably, this may occur in situations where teachers participate in particular instructional interventions to promote deep understanding for students or simply try to adapt their teaching to national and international initiatives describing educational goals and skills required for the 21st century (e.g., CCSSO, 2010; OECD, 2013). Teachers may also regard deep understanding and reasoned argumentation through inquiry dialogue as relevant to their students but, at the same time, adopt inconsistent aims and judge incompatible processes as reliable for them. For example, teachers may adopt the (non-epistemic) aim of high scores on high-stakes tests for their students, and teachers may consider receiving the correct solution through monologic (i.e., one-way) delivery a reliable process for their students to achieve that aim. This is likely to interfere with their efforts to achieve deep understanding for their students by engaging them in reasoned argumentation through inquiry dialogue, however. Supporting teachers in developing their epistemic cognition so that it facilitates rather than constrains the teaching of deep understanding through classroom dialogue may thus be needed. In the following, we briefly highlight the potential role of reflection in this process.

According to Dewey (1933), reflective thinking occurs when individuals confront open problems and carefully consider their beliefs or assumptions in light of supporting evidence. Such thinking has especially been highlighted within the reflective judgment model of King and Kitchener (1994, 2004). Based on their findings, these authors suggested that reflective thinking may be promoted by introducing open, controversial problems and having individuals "examine their assumptions, gather and interrogate the available evidence from multiple perspectives, and be 
responsible for offering their own conclusions of the evidence" (King \& Kitchener, 2004, p. 16).

Particularly relevant to changing teachers' epistemic cognition is the 3R-EC framework of epistemic reflexivity proposed by Lunn Brownlee and colleagues (Cyprus ASC, 2015; Lunn Brownlee, Ferguson, \& Ryan, this issue; Lunn Brownlee \& Schraw, in press; Lunn Brownlee, Schraw, Walker, \& Ryan, 2016). In this framework, teachers' reflection on their epistemic beliefs (i.e., their beliefs concerning the nature of knowledge and the process of knowing) and epistemic thinking in the context of their teaching practice are seen as a means to develop more adaptive epistemic cognition that has instructional implications. For example, teachers may reflect, individually and collectively, on their beliefs and thinking about epistemic aims and reliable processes in the context of their dialogic teaching practice, realizing that their own aims and reliable processes need to be calibrated with the aims and reliable processes they are trying to implement through their teaching. In turn, this calibration process, fueled by reflection in action (i.e., reflexivity), may lead to epistemic cognition among teachers that better supports the epistemic aim of deep understanding and the reliable process of reasoned argumentation for their students (for further discussion of the 3R-EC framework of epistemic reflexivity, see Lunn Brownlee et al., this issue).

In summary, this section has shown that several theoretical frameworks need to be considered and integrated in order to understand how the epistemic aim of deep understanding can be achieved by students when teachers support their engagement in reasoned argumentation embedded in dialogic practice. Moreover, the described frameworks highlighted how teachers' epistemic cognition can facilitate or constrain this process, and how teachers' epistemic cognition can be developed through reflection on their own thinking about aims and processes to achieve them in the context of teaching. Specifically, we described how literacy theorists (Britt et al., 2013; Goldman et al., 2016) have considered deep understanding to involve argumentation. Then, we connected these constructs (i.e., 
deep understanding and argumentation) to epistemic cognition by showing how theorists within epistemic cognition (Chinn et al., 2011, 2014) have considered people's thinking about deep understanding and argumentation components of epistemic cognition. Further, to link these ideas about deep understanding and argumentation to instructional practice, we discussed theory concerning the role of inquiry dialogue and dialogic practice in fostering the kind of argumentation that can be considered to reliably produce deep understanding among students (Gregory, 2006; Walton, 1998). To explain why teachers still may find it challenging to teach deep understanding by engaging students in argumentation through inquiry dialogue, we drew on Buehl and Fives' (2016) framework for teachers' epistemic cognition, discussing ways that teachers' thinking about epistemic aims and reliable processes for achieving those aims may impact their instructional practices. Finally we drew on theoretical assumptions regarding reflection, especially the 3R-EC framework of reflexivity by Lunn Brownlee et al. (2016, this issue), to discuss how teachers' epistemic cognition (i.e., their thinking about epistemic aims and reliable processes) may be changed to facilitate rather than constrain their teaching of deep understanding through argumentation and dialogue.

In the following sections, we review relevant research in light of this theoretical background analysis and discuss implications for instructional intervention work, teacher professional development, and teacher education. Thus, in reviewing research, we explore the extent to which the theoretical assumptions synthesized above have empirical support by considering studies on the effects of argumentation and dialogue on deep understanding, studies linking teachers' epistemic cognition to their instructional practice and student understanding, and studies aiming to change teachers' epistemic cognition and promote their use of argumentation and dialogue in classrooms. In discussing implications for teacher professional development and teacher education, we highlight the importance of epistemic reflexivity - that is, reflection on epistemic cognition as it directly relates to 
teaching practice - in accordance with the 3R-EC framework that is the cornerstone of this special issue.

\section{ARGUMENTATION THROUGH DIALOGUE: POTENTIAL AND CHALLENGES}

A range of empirical studies on the effectiveness of engaging students in argumentation through dialogue has reported positive results, with individual learning gains including highlevel comprehension of texts (Murphy, Wilkinson, Soter, Hennessey, \& Alexander, 2009), science and math achievement (Adey \& Shayer, 2015; Zohar \& Nemet, 2002), enhanced conceptual understanding of disciplinary concepts and principles (Asterhan \& Schwarz, 2007; Nussbaum \& Sinatra, 2003), improved non-verbal reasoning (Mercer, Wegerif, \& Dawes, 1999), and better argumentation skills (Reznitskaya et al., 2009; Trickey \& Topping, 2004). For example, in a study involving Grade 9 biology classes in Israel, students in experimental groups learned the subject through engaging in argumentation about dilemmas on human genetics. These students demonstrated significantly better understanding of biological knowledge and related reasoning skills compared to control students who learned the same content through traditional methods (Zohar \& Nemet, 2002).

Similarly, Reznitskaya and colleagues (2009) discussed the results of four studies that used an established dialogue-based approach called Collaborative Reasoning (CR). During CR, students in elementary language arts classrooms gather in small groups to discuss big, contestable questions raised by their readings. Discussion participants engage with these questions by stating their positions, offering reasons, referring to text for evidence, challenging the reasoning of their peers, and responding to challenges of others with rebuttals. During CR discussions, teachers share control over the flow of talk with the students and, as a result, students take on roles traditionally reserved for teachers: they ask questions, self-nominate, and 
evaluate each other's answers. The teacher's role is to support student engagement in collaborative and rigorous argumentation. All four CR studies, reviewed by Reznitskaya et al. (2009), employed the same posttest-only quasi-experimental design, during which experimental students participated in CR and control students continued with their regular reading instruction. Following the intervention, all students were given the same posttest: they wrote an argumentative essay responding to a moral dilemma facing a character in a short story they read as a prompt. The results showed that students who participated in CR discussions wrote essays that contained a greater number of positions, supporting reasons, opposing reasons, and rebuttals than the essays of control students who did not experience CR. The authors concluded that $\mathrm{CR}$ students were able to apply argumentation skills practiced during the discussion in a new task that they performed individually and in writing.

Despite these positive results, researchers have recently criticized typical studies investigating the pedagogical effectiveness of dialogic engagement for rarely focusing on specific causal mechanisms by which reasoned argumentation embedded within classroom dialogue helps to improve individual thinking, understanding, and learning (Asterhan \& Schwarz, 2016; Kuhn, 2015; Wilkinson et al., 2015; Wilkinson \& Son, 2011). That is, with the exception of a few studies that articulated and compared different types of dialogic practices (e.g., Asterhan \& Schwarz, 2007; Felton, Crowell, Liu, 2015), sociocultural theories have been used merely to provide a general research rationale, rather than to experimentally examine the underlying concepts and principles (Wilkinson et al., 2015). Moreover, as pointed out in several recent reviews, few studies of student outcomes could meet 'best-evidence' criteria (Slavin, 1986), thus indicating a pressing need to research the benefits of dialogue-based instruction using methodologically rigorous designs and assessment methods (Howe \& Abedin, 2013; Kyriacou \& 
Issitt, 2008; Wilkinson et al., 2015).

Although the emerging evidence, albeit incomplete, supports the pedagogical potential of argumentation to address ambitious educational goals for students, such as deep understanding of disciplinary knowledge, it is also important to note that positive effects following engagement in reasoned argumentation have not been found in every study and for all outcome variables. Multiple explanations have been offered to explain inconsistency of results, including delayed effects, duration of treatment, student and group characteristics, and features of dialogic engagement (Asterhan \& Schwarz, 2016; Howe, McWilliam, \& Cross, 2005; Reznitskaya et al., 2012). Here, we would like to focus on teachers' implementation of dialogic practice in their classrooms. During dialogue-based instruction, teacher discourse practices must change from explaining established truths and principles to scaffolding student co-construction of knowledge through argumentation. That is, teachers need to be "procedurally strong, but substantively selfeffacing" (Splitter \& Sharp, 1996, p. 306). Instead of 'covering the material,' they need to model, encourage, and support the norms of reasoned discourse to help students strengthen their arguments and reach the most reasonable conclusions. According to Hammer and Schifter (2001), inviting students to discuss their ideas in an open dialogue also requires that teachers recognize strengths and weaknesses in student arguments and share that recognition with students through instruction. Compared to the goals and methods of traditional teaching, often characterized by the use of IRF (Initiation-Response-Feedback) sequences (Applebee, Langer, Nystrand, \& Gamoran, 2003; Kyriacou \& Issitt, 2008), this implies a new teacher role that "comes with different and strenuous intellectual demands" (Hammer \& Schifter, 2001, p. 442). Accordingly, several studies have documented that teachers may struggle with learning new dialogic practices (Alvermann \& Hayes, 1989; Juzwik et al., 2012; Nguyen et al., 2007). For 
example, Alvermann and Hayes (1989) described a 6-month professional development program, consisting of multiple cycles of teacher-researcher planning conferences and analyses of videotaped discussions. Despite their participation in methodical and highly personalized professional development activities, the middle school teachers in this study "exhibited a marked stability in their patterns of verbal exchange" (Alvermann \& Hayes, 1989, p. 331). The researchers noted that the lack of progress might have resulted from conflicts between the recommended practices and the teachers' "experiences, beliefs, and intuitions" (p. 332). Following up on this idea, we suggest that dialogic practices may often be incongruent with existing goals, values, and beliefs teachers have about knowledge and ways of knowing, that is, with their epistemic cognition.

\section{IMPLICATIONS OF TEACHERS' EPISTEMIC COGNITION}

Indeed, a variety of empirical studies have explored whether pre-service and in-service teachers' beliefs more broadly (Liu, 2011; Pajares, 1992; Woolfolk-Hoy, Davis, \& Pape, 2006), and teachers' epistemic cognition in particular, relate to their instructional approaches or selfreported practices and conceptions of teaching (Brownlee, Schraw, \& Berthelsen, 2011; Kang, 2008; Muis \& Foy, 2010; Olafson \& Schraw, 2006; Roth \& Weinstock, 2013; Tsai, 2006) (see Maggioni \& Parkinson [2008] for a review). Research has also been conducted to examine the link between teachers' epistemic cognition, instructional approaches, students' epistemic cognition, and students' learning (e.g., Feucht, 2010; Muis \& Duffy, 2013; Muis \& Foy, 2010; Ryu \& Sandoval, 2012). Although much of this work has not explicitly or directly investigated teachers' thinking about the epistemic aim of deep understanding and the reliable process of reasoned argumentation, we contend that it still may shed light on the major issue discussed in this article, that is, how teachers' epistemic cognition may facilitate or constrain students' 
construction of deep understanding through argumentation.

Typically, researchers who have explored these relations have measured teachers' personal beliefs about knowledge and knowing (i.e., teachers' epistemic cognition for themselves), teachers' beliefs about how students acquire knowledge (i.e., teachers' epistemic cognition for students), or both (Buehl \& Fives, 2016). Indeed, most of what is known about teachers' epistemic cognition is based on teachers' responses to belief questionnaires (Bråten, 2016). Regarding instructional practices, the majority of this work has distinguished between more constructivist practices, such as inquiry dialogue, and more traditional practices, such as direct instruction (Brownlee, Schraw et al., 2011), and has examined whether teachers with more constructivist epistemic cognition, considering knowledge to be tentative, complex, and critically evaluated via argumentation with multiple sources of information, also engage in more constructivist instructional approaches. It has been shown that teachers with more constructivist epistemic cognition may be more likely to engage students in critical reasoning and collaborative construction of knowledge for deep understanding via classroom dialogue (Brownlee, Schraw, et al., 2011; Ryu \& Sandoval, 2012). Moreover, teachers who espouse more constructivist epistemic cognition may be more likely to provide students opportunities to solve ill-structured problems, use strategies that focus on building personal meaning, and link new content to prior knowledge compared to teachers who display less constructivist epistemic cognition (Brownlee, Schraw, et al., 2011). In contrast, teachers with less constructivist epistemic cognition may be more likely to engage in monologic teaching practices that include teacher-directed didactic lectures and to value speed of learning and solving problems quickly over diversity in approach (Bendixen \& Feucht, 2010; Brownlee, Schraw, et al., 2011).

In one exemplary study, Tsai (2006) examined the coherence between teachers' beliefs 
about knowledge in science, their beliefs about teaching, and their instructional practices in science classrooms. From a sample of 40 teacher participants, four eighth-grade physics teachers were selected for in-depth interviews about their beliefs about knowledge and observations of their classroom practices. Teachers were also interviewed about their beliefs about science teaching and learning. To assess teachers' instructional practices, each teacher was observed for eight forty-five minute periods during their science classes. Observations of instructional practices were categorized into six major types on the basis of a minute-to-minute analysis: teacher-directed lecture, tutorial problem practice, in-class exams, laboratory or small-group inquiry activity, interactive discussion and questioning, and other (i.e., off-task talking). Time allocation percentages were then calculated across the six categories as a function of total observed time.

Based on responses to their interviews, teachers were characterized as constructivist, mixed, or positivist in their beliefs about science knowledge, as well as constructivist, mixed, or positivist in their beliefs about student learning. Analyses revealed coherence between teachers' beliefs about science knowledge, student learning, and instructional approaches. Teachers with constructivist beliefs about science knowledge also held constructivist beliefs about student learning. With regard to instructional practices, constructivist teachers focused on students developing a deep understanding and ability to apply content via inquiry activities and interactive discussion. In contrast, teachers with more positivist beliefs spent most instructional time on teacher-directed lectures, tutorials to practice problem solving, or in-class examinations.

Although a number of researchers have explored relations between teachers' epistemic cognition and instructional practices (see Brownlee, Edwards, Berthelsen, \& Boulton-Lewis, 2011), fewer studies have reported relations between teachers' and students' epistemic cognition 
(Muis \& Foy, 2010; Ryu \& Sandoval, 2012; Tsai, 2006) or relations between teachers' epistemic cognition and students' learning (Muis \& Foy, 2010; Ryu \& Sandoval, 2012; Tsai, 2006), which is relevant to the issue of whether teachers' epistemic cognition may impact students' construction of deep understanding. Rather, the majority of work including students has assessed how teachers' instructional approaches relate to students' epistemic cognition (e.g., Feucht, 2011; Tillema, 2011; see Muis, Trevors, \& Chevrier, 2016). The general trend in this line of research is that more constructivist instructional approaches predict greater constructivist epistemic cognition among students, whereas more traditional instructional approaches relate to less constructivist epistemic cognition among students (Muis et al., 2016). Moreover, more constructivist instructional approaches seem to foster students' critical reasoning and argumentation, which subsequently lead to better learning outcomes such as deeper understanding of the content (Muis \& Duffy, 2013; Ryu \& Sandoval, 2012).

For example, Ryu and Sandoval (2012) examined whether elementary students' sustained participation in scientific argumentation was related to changes in their epistemic cognition concerning science. Specifically, these researchers were interested in how children appropriated four epistemic criteria central to understanding scientific argumentation: (1) causal structure (i.e., a scientific argument should contain causal claims), (2) causal coherence (i.e., scientific claims advance chains of causal inferences); (3) citation of evidence (i.e., a good argument cites data that claims are meant to explain), and (4) evidentiary justification (i.e., good arguments explicate and justify relationships between claims and evidence). They purposefully sampled one teacher, Mrs. Green, who set the epistemic aim of deep understanding for her students to be achieved through the reliable process of argumentation during science learning.

To achieve this epistemic aim, Mrs. Green began each major science unit by asking 
students to create big ideas and questions. Students were initially given structured guided activities, but over time those activities became more open-ended, less structured inquiry activities where students designed their own questions, designed and tested their own experiments, and presented their findings to the rest of the class. As students engaged in their experiments, Mrs. Green continually asked students questions such as "How do you know? How do you convince others?" to encourage them to think more about claims and how to justify those claims. She engaged students in whole-class discussions where students would decide on the importance of having evidence to back up claims, and what good evidence entailed. Over the course of the academic year, Mrs. Green prompted students to develop norms of scientific argumentation with the emphazised goal of persuasion. She continually asked students to convince each other by backing up claims, showing evidence, and providing evidentiary justification while simultaneously engaging students in discussions of what each of those elements entailed.

To assess changes in students' epistemic understanding of scientific argumentation, Ryu and Sandoval (2012) used a pretest-posttest design. At the beginning and end of the academic year, students were given the same argument construction task where they had to evaluate four pairs of arguments in which each pair varied on only one of the targeted epistemic criteria described above. Specifically, students were asked to choose the best argument from each pair, choose the criterion they believed made it better, and write a reason for their choice criterion. To map change in students' epistemic cognition to classroom dialogue, classrooms observations were conducted each weak throughout the year. Ryu and Sandoval (2012) reported that students improved significantly on three of the four epistemic criteria: causal coherence, citation of evidence, and evidentiary justification. They attributed these changes to the coordination of 
argumentation norms and targeted epistemic criteria. That is, students developed a deep understanding of scientific argumentation (i.e., epistemic aim) through argumentation embedded in inquiry dialogue (i.e., reliable process).

With regard to empirical evidence of relations between teachers' and students' epistemic cognition, Muis and Foy (2010) examined relations between teachers' epistemic cognition and elementary students' epistemic cognition and between teachers' epistemic cognition and students' learning and self-efficacy beliefs, achievement goal orientations, and achievement in mathematics. In this way, this study addressed to what extent teachers' epistemic cognition can predict beliefs, orientations, and achievements likely to facilitate or constrain disciplinary (i.e., mathematics) understanding among students. Fifty-five elementary school teachers from the fourth and fifth grades completed Buehl, Alexander, and Murphy’s (2002) Domain-Specific Beliefs Questionnaire. From the same teachers' classrooms, 131 elementary students participated and completed a 15-item questionnaire designed to measure their beliefs about the certainty and simplicity of mathematics knowledge, their beliefs in the need for effort to learn mathematics, and their mastery and performance goal orientations. Students also completed a task-specific questionnaire designed to assess their self-efficacy for successfully completing mathematics problems similar to those they were about to solve.

Results from structural equation modeling revealed the more teachers believed knowledge about mathematics should be deeply understood and integrated into existing knowledge structures, the less students held beliefs likely to constrain their disciplinary understanding, specifically beliefs in the certainty and simplicity of mathematics knowledge. Additionally, teachers' beliefs about the need for effort to learn mathematics positively predicted students' beliefs about the effort to learn mathematics. Interestingly, both teacher belief 
dimensions also positively predicted students' mathematics achievement, which suggests that teachers' beliefs relate to students' beliefs and to student achievement. As Muis and Foy (2010) proposed, this is likely due to instructional strategies teachers implement in their classrooms along with explicit messages that teachers relay to their students to focus on deep understanding and effortful learning.

However, as Buehl and Beck (2015) reported, although many studies have found support for the link between teachers' beliefs and instructional practice, the nature and strength of relations have been challenged given that some studies have demonstrated weak to no relationship (Lederman, 1999; Levitt, 2001; Lim \& Chai, 2008; Liu, 2011; Olafson \& Schraw, 2006; Schraw \& Olafson, 2002; White, 2000). Several constraints have been identified that help explain the lack of coherence between beliefs and practice such as social factors, situational constraints, teachers' level of experience, intentions, lack of self-efficacy in being able to carry out more constructivist approaches, perceptions of students' ability, and a reliance on districtmandated curriculum and teaching strategies (Buehl \& Beck, 2015; Muis \& Foy, 2010). In addition to these constraints, as Windschitl (2002) suggested, a key issue may be a lack of calibration between teachers' epistemic cognition and constructivist, dialogue-based instructional practices. That is, if teachers do not think that deep understanding is a valuable epistemic aim that can be achieved through a reliable process such as argumentation, then they likely will not set that aim nor engage students in reasoned argumentation through classroom dialogue. As such, it seems critical to support the calibration of teachers' epistemic cognition with instructional practices. In the next section, we highlight intervention research designed to foster constructivist epistemic cognition among teachers.

\section{CHANGING TEACHERS’ EPISTEMIC COGNITION}


As previously noted, if students are to be able to deal with complex, controversial issues, it seems critical that their understanding is fostered through instructional approaches that engage them in argumentation through dialogue. However, as Buehl and Fives (2016) have argued, this requires that teachers develop epistemically informed praxis. Such praxis includes the enactment of instructional strategies and assessments that are guided by the process of epistemic cognition to assist others in achieving specific epistemic aims, such as deep understanding, through reliable processes, such as reasoned argumentation (Chinn et al., 2014). Over the past several decades, a number of interventions targeting both students' and teachers' epistemic cognition have been conducted to explore how epistemic cognition can be fostered toward more constructivist perspectives. As Muis et al. (2016) noted, the conceptual change paradigm has been a guiding model for many interventions within the educational psychology literature (Gill, Ashton, \& Algina, 2004; Ferguson \& Bråten, 2013; Kienhues, Bromme, \& Stahl, 2008; Muis \& Duffy, 2013; Porsch \& Bromme, 2011), and interventions have included the use of refutation text (Gill et al., 2004; Kienhues et al., 2008), scientific inquiry (Metz, 2011), and argumentation (Herrenkohl \& Cornelius, 2013; Muis \& Duffy, 2013; Ryu \& Sandoval, 2012; Wilkinson et al., 2016), to name a few (see Bendixen [2016], Lunn Brownlee et al. [2016] and Muis et al. [2016] for reviews of interventions).

With regard to teachers' epistemic cognition, Schraw, Lunn Brownlee, and Olafson (in press) reviewed a variety of studies and concluded that, coupled with the various approaches that have been used to support the development of teachers' epistemic cognition, explicit reflection on beliefs seems critical to ensure epistemic change and calibration of epistemic cognition with constructivist instructional practices (see also Buehl \& Beck [2015], and Lunn Brownlee et al. [2016]). This idea has been further developed and refined within the 3R-EC framework of 
epistemic reflexivity (Cyprus ASC, 2015; Lunn Brownlee et al., this issue). Likewise, Adibelli and Bailey (in press) recommended that once teachers have reflected on their own epistemic cognition, they should be provided the opportunity to experience teaching that is aligned with their epistemic cognition. Gholami (in press) further argued that one way to promote sustained change and calibration is through use of dialogic teaching partners that can provide a mechanism by which reflection on classroom practices may take place.

Addressing this issue, Windschitl, Thompson, and Braaten (2008) examined the effects of a model-based inquiry program designed to change teachers' epistemic cognition about science. The inquiry program included six design principles for learning environments with the epistemic aim of fostering learners' participation in material and dialogic activities that characterize scientists' knowledge generation. The six principles included: (1) model prototypical cases of disciplinary activity and discourse early in the timescale of instruction; (2) problematize content by encouraging students to pose problems, hypothesize, and challenge ideas; (3) give students authority whereby they produce knowledge and take ownership of that knowledge; (4) use reasoned argumentation within recurring social contexts; (5) provide relevant resources, including time, materials, and information that explicitly demonstrates the language used within the discipline; and, (6) hold students accountable to disciplinary norms, including appropriate forms of argument. The program was integrated into pre-service teachers' coursework, after which they were asked to implement what they learned into their teaching practicums.

Using a naturalistic inquiry design, Windschitl et al. (2008) explored how teacher participants' forms of reasoning and discourse changed over a 15-month period, and assessed the conditions that supported these changes. To measure teachers' epistemic cognition about science prior to the program, teachers were asked a series of interview questions that focused on the 
function of models, the use of models in instruction, the characteristics of authentic investigative science, and their school-related experiences in doing science. Other data sources included videotaped and written artifacts from the guided inquiry that took place during the first two class periods as well as audio-recordings of small group discussion on the roles and functions of scientific models, among several others. Post-program assessment of teachers' epistemic cognition and teaching practices included a combination of written reflections on the inquiry process, end-of-course interviews, and observations of their teaching methods in the following semester as they began their teaching practicums.

Findings revealed that initially, less than half of the teachers displayed epistemic cognition congruent with that of experts in regard to the nature and function of models. However, by the end of the program, the vast majority of teachers reconceptualized the interrelated roles of models, theory, evidence, and arguments (i.e., attempts to support or refute explanations based on evidence) in scientific inquiry. This change in epistemic cognition ultimately led to a shift in teachers' epistemic aims for their students from an initial goal of "proving" a hypothesis, to testing and revising explanatory models. Findings from teaching episodes also revealed a coherence between teachers' epistemic cognition and their instructional practices; that is, teachers attempted "epistemically ambitious" classroom practices, meaning that they challenged students to develop testable models of natural phenomena and gather evidence to link observations with underlying explanatory processes. Interestingly, throughout this time, teachers had the opportunity to reflect on changes in their epistemic thinking with other teachers and noted that this was an important feature that helped them to develop their thinking about science. This highlights the importance of dialogic teaching partners in the process of epistemic change (Gholami, in press). We further discuss implications for teacher education and teacher 
professional development next.

\section{IMPLICATIONS FOR TEACHER EDUCATION AND PROFESSIONAL DEVELOPMENT}

In an analysis of teacher professional development in the US, Elmore (2002) claimed that "few people willfully engage in practices that they know to be ineffective; most educators have good reasons to think that they are doing the best work they can" (p. 19). We add that not many teachers would consider transitory knowledge of disconnected facts to be the ultimate purpose of their students' education; yet, their typical discourse practices often work to achieve just that. Accordingly, teacher education and professional development (TEPD) programs in dialoguebased instruction need to help future and current practitioners recognize the inconsistencies in their intended versus enacted beliefs and to support non-trivial and lasting changes in teachers' use of language to support students' engagement in reasoned argumentation.

Core features of more effective TEPD programs aimed to foster dialogic practices include arming teachers with a repertoire of discursive moves, involving teachers in co-inquiry about their practice, providing opportunities for collaborative goal setting and co-planning of lessons, having teachers publicly practice, or rehearse, instructional activities, supporting reflection on teachers' own practice through analysis of videos and transcripts, and using dialogue-based pedagogy during professional development interventions (Goldenberg \& Gallimore, 1991; Hennessy, Mercer, \& Warwick, 2011; Kazemi, Ghousseini, Cunard, \& Turrou, 2015; Kucan, 2007; Lampert et al., 2013; Michaels \& O’Connor, 2015; Reznitskaya \& Wilkinson, 2015b). For example, Michaels and O'Connor (2015) presented teachers with families of "productive talk moves" that can be used as tools to help students articulate their own ideas and engage with others. A family of "press for reasoning" moves, for instance, includes questions such as "Why do you think that? What's your evidence? What led you to that conclusion?" (Michaels \& 
O'Connor, 2015, p. 348). These talk moves are intended to prompt students to elaborate and justify their ideas, making them more explicit and accessible. These families of talk moves were later incorporated into the Accountable Talk approach to school reform and used in other TEPD programs (Michaels, O’Connor, Hall, \& Resnick, 2002; Reznitskaya \& Wilkinson, 2015b; Wolf, Crosson, \& Resnick, 2006).

Most TEPD programs designed to foster dialogue-based instruction do not include teacher epistemic cognition as a key target of their interventions. Yet, core activities of these programs offer opportunities for teachers to explore their epistemic cognition and calibrate it with new discourse practices. According to the 3R-EC framework for changing personal epistemologies proposed by Lunn Brownlee and colleagues (2016, this issue), teachers should engage in a cyclical multi-step process of reflexivity, during which they identify a problem of practice, critically reflect on several options to address it, decide on a specific action, try it out in a classroom, and evaluate its effectiveness. As discussed by Lunn Brownlee et al. (this issue), a key element in this process of change is teachers' reflection on epistemic aims and reliable processes as they directly relate to teaching practices. In TEPD programs supporting dialogic practices, teachers can engage in this process of reflexivity during analysis of their own practice, which is often conducted as part of coaching sessions.

During coaching, teachers examine their own class discussions with the help of a peer or an expert discourse coach (e.g., Alvermann \& Hayes, 1989; Juzwik et al., 2012; Kucan, 2007; Reznitskaya \& Wilkinson, 2015b; Roskos \& Boehlen, 2000). Typically, coaching sessions focus on the use of recommended discourse practices or talk moves (Michaels \& O’Connor, 2015), which may help teachers engage students in thinking and reasoning to foster deep understanding of complex and controversial issues. Although epistemic considerations may spontaneously 
come up during coaching sessions, more targeted and systematic approaches may be necessary.

In studies of teacher professional development aimed to support the use of inquiry dialogue in elementary school classrooms, Reznitskaya and colleagues (Reznitskaya \& Wilkinson, 2015a, 2015b; Wilkinson et al., 2016) developed a coaching protocol, in which they outlined principles and procedures that coaches should use to help promote changes in teacher epistemic cognition and their discourse practices. For example, coaches should help teachers work closely with students' arguments or parts of their arguments (i.e., positions, reasons, evidence, challenges, rebuttals). That is, together with the coach, teachers should reconstruct the arguments made by their students during the previous discussion and identify their strengths and weaknesses. This is because teacher facilitation moves are best understood in the context of group argumentation. By carefully examining students' arguments, teachers get to reflect on their use of talk and identify opportunities missed or taken to enhance the quality of argumentation. In other words, engaging in the analysis of students' arguments helps teachers understand the underlying functions of certain talk moves, thus making their practice purposeful, rather than formulaic. In addition, critical evaluation of students' arguments orients teachers towards the 'truth-seeking' aim of inquiry dialogue (i.e., to find the most reasonable answer and construct deep understanding), thus helping them build connections between their epistemic cognition and discourse practices. Towards the end of the coaching meeting, the teacher and the coach should co-construct a specific goal for the teacher to work on during the next class discussion. This goal gets recorded and revisited during the following coaching session, which engages teachers in continued reflection on their professional choices.

We encourage other researchers to develop and test the effectiveness of coaching procedures that can help teachers better calibrate their epistemic cognition and instructional 
decisions. Such procedures can be explicitly framed by the 3R-EC model (Lunn Brownlee et al., this issue), emphasizing teachers' reflection on epistemic aims and reliable processes in the context of their classroom discourse practices. Presumably, without calibration between teachers' epistemic cognition and recommended discourse practices, any changes in classroom discourse are likely to be superficial and short-lived, representing a simple mimicking of new talk moves by teachers who "adopt apparently novel dimensions in instruction while preserving fundamental ideas about subject matter, teaching, and learning” (Windschitl, 2002, p. 139).

Another common activity of TEPD programs in dialogue-based instruction is the use of co-inquiry (Hennessy et al., 2011; Reznitskaya \& Wilkinson, 2015b; Saunders, Goldenberg, \& Hamann, 1992). For example, Hennessy and colleagues (2011) described an innovative approach to professional development where they partnered with three practitioners from different disciplines to engage in critical co-inquiry into teachers' use of dialogic practice. In this project, researchers did not provide teachers with "research-based proposals for practice" (Hennessy et al., 2011, p. 1907). Instead, they "collaborated with practitioners in intensive critical scrutiny of practice," during which "differing areas of professional expertise were valued and deliberately exploited" (Hennessy et al., 2011, p. 1908).

Such co-inquiry into the use of dialogue-based instruction can also be a promising mechanism for advancing epistemic cognition among teachers (Schraw, 2001; Valanides \& Angeli, 2011). At the same time, several researchers have identified possible limitations of inquiry for supporting changes in epistemic cognition (Bråten, 2016; Khishfe \& Abd-El-Khalick, 2002; Tabak \& Weinstock, 2011). For example, Khishfe and Abd-El-Khalick (2002) suggested that engagement in inquiry alone may not be sufficient and should be supplemented with explicit reflection on the epistemic dimensions of the experience. According to the 3R-EC framework 
(Lunn Brownlee et al., this issue), such reflection should target epistemic aims and reliable processes and take place in the context of teaching. The effectiveness of inquiry may also be diminished when participants misunderstand and misapply it, assuming that it simply provides opportunities for voicing individual opinions, which often remain disconnected and unexamined (Tabak \& Weinstock, 2011). We need more studies that systematically examine the use of coinquiry in TEPD contexts, focusing on the effectiveness of this approach for calibrating epistemic cognition with discourse practices.

In addition, we suggest that teachers participating in professional development will benefit from having a clear, theoretically-grounded understanding of normative types of dialogue that can support student engagement in reasoned argumentation. For example, in recent work with elementary school teachers in language arts classrooms, Reznitskaya and colleagues (Reznitskaya \& Wilkinson, 2015b; Wilkinson et al., 2016) drew heavily on the conception of inquiry dialogue proposed by Walton (1998). During study group meeting with teachers, the goals and norms of inquiry dialogue were discussed and contrasted with other dialogue types, such as those designed to win over opponents (as in persuasion dialogue) or to release negative emotions (as in eristic dialogue). Teachers were then invited to collaboratively develop 'ground rules' for discussions and to engage students in continuous revisions of these rules. Consider, for example, the way a teacher-participant in this TEPD program reviewed ground rules with her fifth-grade students before starting a discussion:

"I really want you thinking about... are we building this argument together? Remember how we talked about that, sometimes, it's almost like "Well, I think this," and "I think this," and "I think this." Popcorn, almost? It shouldn't be like that. It should be listening and building an argument to come to a decision together. So, are we listening and 
responding to what people say to build an argument, rather than just having this popcorn talk going on?... Can anyone think of anything else, maybe, that we should be looking for? Jerry, what were you going to say?” (Reznitskaya, Bråten, \& Muis, 2017) This teacher's notion of "popcorn talk," during which individual ideas pop up in a haphazard and disconnected manner, perfectly captures problems with classroom dialogue that merely focuses on sharing of opinions. During such dialogue, almost anything goes; students misinterpret evidence, make logical errors, or rely on unwarranted assumptions. They leave the discussions having made little progress towards finding the most reasonable answer, and possibly, with the belief that there is no way to make progress. In contrast, the quote shows that this teacher challenged her students to engage with each other's thinking by "listening and responding to what people say," and reminded them of the collective goal for the discussion: "to build this argument together." Such clarity in goals and norms of dialogic engagement may not only result in a more focused and critical discussion, but it can also support students in developing epistemic cognition that is better aligned with the goals and practices of inquiry dialogue. In fact, changes in epistemic cognition of not only teachers, but also their students, should be seen as an important outcome when evaluating TEPD interventions focused on promoting dialogue-based instruction.

The excerpt above also demonstrates possibilities for innovative ways to measure epistemic cognition of teachers when evaluating the impact of TEPD programs focused on dialogue-based instruction. Several recent studies critically reviewed existing approaches to assessing epistemic cognition and made excellent recommendations for improvements (Mason, 2016; Olafson \& Schraw, 2010; Yadav, Herron, \& Samarapungavan, 2011). For example, researchers explored using think-aloud methodology, scenario-based assessments, and measures 
of enacted epistemology to reveal more nuanced and rich conceptions of knowledge and knowing held by the teachers. Following these developments, we want to reiterate the need to use more varied and sensitive measures of epistemic cognition that are directly relevant to specific goals of the intervention and related to classroom contexts. Such measures are more likely to capture important changes in epistemic cognition resulting from TEPD programs. For example, in the studies of TEPD in dialogue-based instruction, researchers can examine epistemic cognition as it is enacted in a classroom when teachers begin to adopt new discourse practices. For instance, teacher explanations of the ground rules for the discussion to her students may be coded to reveal a move towards more adaptive epistemic cognition. Alternatively, using scenario-based instruments, researchers could have teachers view segments of videotaped discussions to have them think aloud about the underlying assumption of selected talk moves or other discourse practice.

Finally, research on TEPD programs designed to promote consistency between teachers' epistemic cognition and their practice should take into account external forces that affect classroom instruction. Such forces include the unprecedented expansion of high-stakes standardized testing and the increased use of scripted curricula mandated by school districts (Muis \& Foy, 2010; Schraw \& Olafson, 2002). In the recent studies of teachers' learning and use of inquiry dialogue in elementary school classrooms in the US by Reznitskaya and colleagues (Reznitskaya \& Wilkinson, 2015a, 2015b; Wilkinson et al., 2016), it was found that even the most enthusiastic teachers lamented about having no time to try out and implement new discourse practices. These teachers were worried about school administrators and parents who, in the words of one participant, "breathe down our necks and want us to prepare the kids for the test" (Reznitskaya et al., 2017). Although teachers and researchers typically have little control 
over such external forces, it is important to disentangle and document their potential role in undermining professional development efforts. Additional sources of the misalignment between teachers' epistemic cognition and their use of dialogue-based instruction may include individual teacher characteristics, ranging from years of teaching experience to assumptions about students' abilities to engage in higher-order thinking (Lederman, 1999; Schraw \& Olafson, 2002). We recommend that more research, including in-depth qualitative studies, be conducted to identify both external and individual factors that either support or preclude teachers from effectively calibrating their epistemic cognition with advocated classroom practices.

\section{CONCLUSIONS AND FUTURE DIRECTIONS}

The theory and research described in this article highlight the importance of teachers' thinking about epistemic aims and reliable processes for students' understanding of controversial issues about which "reasonable people reasonably disagree” (King \& Kitchener, 2004, p. 5). Consideration of frameworks within literacy, epistemic cognition, argumentation and dialogue, and reflective thinking, as well as related empirical evidence, suggests that engaging students in reasoned argumentation through classroom dialogue has the potential to foster deep understanding among students; yet, teachers may need to reflect on their own epistemic cognition in the context of such teaching in order to calibrate it with the aims and reliable processes that they try to implement in their classrooms. The theory and research that we reviewed also suggest that teacher education and professional development programs support future and practicing teachers in developing epistemic cognition that is adapted to the aim of deep understanding and reasoned argumentation as a reliable process to achieve that aim. Further, our review suggests that teachers' own epistemic cognition is targeted and assessed as part of interventions designed to promote dialogue-based instruction. 
As demonstrated by the reviewed theory and research, however, there is still much to be explicated and investigated to translate our preliminary insights into actual instructional designs for teacher education and professional development, as well as for efforts to foster deep understanding among students by engaging them in reasoned argumentation. Thus, although we have shown that integration of various relevant theoretical frameworks, including the disciplinary literacy framework of Goldman and colleagues (2016), the framework for epistemic cognition by Chinn and colleagues $(2011,2014)$, theoretical work on the nature of dialogues by Walton (Walton, 1990; Walton \& Macagno, 2007), Buehl and Fives' (2016) framework for teachers' epistemic cognition, and the 3R-EC framework of reflexivity by Lunn Brownlee and colleagues (2016, this issue), can provide a meaningful account of how the different constructs hang together, this is but the beginning of important theoretical work to forge a coherent framework that explains relationships among deep understanding, argumentation, dialogue, teacher epistemic cognition, and teacher reflection in action. Of note is that further theoretical clarification needs to proceed in parallel with empirical work to substantiate postulated relationships among these constructs.

For example, it is important to note that causal evidence for the claim that engaging students in reasoned argumentation embedded within classroom dialogic practice will improve individual understanding is not abundant (Asterhan \& Schwarz, 2016; Kuhn, 2015; Wilkinson et al., 2015; Wilkinson \& Son, 2011). This is partly because a lack of rigorous experimentation characterizes research in this area (Asterhan \& Schwarz, 2016; Kuhn, 2015). In particular, more research that meets "best evidence" criteria (Slavin, 1986) and, at the same time, targets individual students' deep understanding of controversial issues discussed across multiple information resources as the outcome variable is highly needed. Yet, while such experimental 
work is needed to draw firmer conclusions regarding causal relationships, explanatory mixed methods designs (Creswell \& Plano Clark, 2007) may be needed to more fully explain quantitative findings. Because engaging students in reasoned argumentation through classroom dialogue also poses new challenges to many teachers (Alvermann \& Hayes, 1989; Hammer \& Schifter, 2001; Juzwik et al., 2012), teachers' roles in facilitating or constraining student understanding in such instructional contexts also need to be further researched through comprehensive implementation data.

Importantly, this focus on teachers' roles should also include attention to their epistemic cognition. Although teachers' beliefs about knowledge and knowing have been linked to classroom instructional approaches, this body of work has not directly targeted teachers' thinking about epistemic aims such as deep understanding and reliable processes such as reasoned argumentation. Also, research investigating the extent to which teachers' instructional practice mediates the effects of their epistemic cognition on students' understanding is still conspicuous by its absence. Moreover, the extent to which a lack of calibration between teachers' epistemic cognition and the consideration of epistemic aims and reliable processes that underlies dialoguebased instruction actually may impact students' understanding is still a topic that requires more attention from researchers. In future studies, an explicit focus on teachers' epistemic ideals, such as the criteria they use to judge whether the epistemic aim of deep understanding has been achieved, also seems pertinent. In some instances, teachers might adopt the aim of deep understanding but still use inadequate criteria to judge whether this aim has been achieved. This might occur, for example, if they consider deep understanding to be evidenced by recall of information rather than by making sense of and evaluating arguments to build integrated understanding from multiple sources (Britt et al., 2013; Goldman et al., 2016). 
Further, intervention work aiming to support practitioners and student teachers in developing their epistemic cognition, although promising, has not directly targeted the calibration of teachers' epistemic cognition and the epistemic aims and reliable processes underlying efforts to engage students in reasoned argumentation through classroom dialogue. In addition, more work is needed to substantiate preliminary findings indicating that teachers' collective reflection on their epistemic cognition in action, that is in the context of their dialogic teaching practice, is a viable path to achieving better calibration between their epistemic cognition and instruction that reflects the aim of deep understanding and the reliable process of reasoned argumentation. Hopefully, the 3R-EC framework featured in this special issue will inspire much future work in this area.

Finally, in discussing the implications of our analysis for teacher education and professional development, we suggested several ways to support the development of epistemic cognition among teachers participating in interventions designed to engage students in reasoned argumentation through classroom dialogue. Hopefully, direct and systematic targeting of teachers' epistemic cognition in such instructional programs will lead to adaptive changes in teachers' epistemic cognition and, in turn, improve the effectiveness of such programs to promote deep understanding among students. To what extent this actually will happen is currently not known, however. Importantly, answering this question also requires further research to develop sensitive, preferably behavioral (i.e., beliefs-in-action type) measures of teachers' epistemic cognition that can be included on a par with assessments of individual students' understanding when evaluating the effects of dialogue-based interventions.

Rather than focusing on each of the issues highlighted in this final section in isolation, more comprehensive programs of research that address all issues in combination are particularly 
needed. This requires integrated efforts by researchers in such areas as literacy, epistemic cognition, argumentation, dialogue-based teaching, and teacher education. Hopefully, the present article will provide an impetus for such integrated research efforts that, in turn, can drive the development of more refined, coherent frameworks with clear educational applicability. 


\section{NOTES}

${ }^{1}$ The term "adaptive" has largely replaced the term "sophisticated" in theory and research on epistemic cognition. The reason is that the term "sophisticated" may indicate that some forms of epistemic cognition are universally effective or availing independent of context, while the term "adaptive" signals that what is sophisticated epistemic cognition in one context may not necessarily be so in other contexts (see, e.g., Bråten, Strøms $\varnothing$, \& Samuelstuen, 2008; Hofer \& Sinatra, 2010).

2 The epistemic cognition framework proposed by Chinn and colleagues $(2011,2014$; Chinn \& Rinehart, 2016) consists of several components and subcomponents. One of the main components, epistemic ideals, refers to "the standards that a person uses to evaluate whether epistemic ends have been achieved" (Chinn et al., 2014, p. 426), and includes epistemic cognition concerning the structure of knowledge and the justification for knowing (cf., Hofer \& Pintrich, 1997). While epistemic ideals and its subcomponents may also be relevant aspects of teachers' epistemic cognition that potentially impact their teaching practice, our focus is on the epistemic aim of deep understanding and the reliable process of reasoned argumentation in this article. This is because our discussion centers on how teachers' thinking about these specific aspects of epistemic cognition may, in turn, influence students' construction of deep understanding by means of evidence-based argumentation with multiple sources of information.

${ }^{3}$ In this article, we treat epistemic cognition and the process of argumentation as distinct constructs. Specifically, we regard people's thinking about argumentation as a reliable process to achieve particular epistemic aims as epistemic cognition, not argumentation per se. This approach finds support in Chinn et al.'s (2011, 2014; Chinn \& Rinehart, 2016) discussions of their framework of epistemic cognition. At the same time, we acknowledge that Chinn and 
colleagues also described uses of reliable processes in ways suggesting that they considered enacted reliable processes as part of epistemic cognition, which seems to imply theoretical overlap between epistemic cognition and argumentation. Our decision to regard people's thinking (cognitions or conceptions) about argumentation, rather than argumentation per se, as epistemic cognition, is thus based on an interpretation of Chinn et al.'s framework that may be disputed. However, this interpretation is consistent with our definition of epistemic cognition as concerning how individuals think about what they know, what knowledge is, and how they know what they know (Sandoval et al., 2016). 


\section{REFERENCES}

Adey, P., \& Shayer, M. (2015). The effects of cognitive acceleration. In L.B. Resnick, C.S.C. Asterhan, \& S.N. Clarke (Eds.), Socializing intelligence through academic talk and dialogue (pp. 127-140). Washington, DC: American Educational Research Association.

Adibelli, E., \& Bailey, J.M. (in press). Exploring the factors mediating changes in elementary teachers' epistemological beliefs about teaching science. In G. Schraw, J. Lunn Brownlee, L. Olafson, \& M. Vanderveldt (Eds.), Teachers' personal epistemologies: Evolving models for transforming practice. Charlotte, NC: Information Age.

Alvermann, D.E., \& Hayes, D.A. (1989). Classroom discussion of content area reading assignments: An intervention study. Reading Research Quarterly, 24, 305-335.

Applebee, A.N., Langer, J.A., Nystrand, M., \& Gamoran, A. (2003). Discussion-based approaches to developing understanding: Classroom instruction and student performance in middle and high school English. American Educational Research Journal, 40, 685730.

Asterhan, C.S.C. (2013). Epistemic and interpersonal dimensions of peer argumentation: Conceptualization and quantitative assessment. In M. Baker, J. Andriessen, \& S. Jarvela (Eds.), Affective learning together (pp. 251-272). New York: Routledge.

Asterhan, C.S.C., \& Schwarz, B.B. (2007). The effects of monological and dialogical argumentation on concept learning in evolutionary theory. Journal of Educational Psychology, 99, 626-639.

Asterhan, C.S.C., \& Schwarz, B.B. (2016). Argumentation for learning: Well-trodden paths and unexplored territories. Educational Psychologist, 51, 164-187.

Bendixen, L.D. (2016). Teaching for epistemic change in elementary classrooms. In J.A. Greene, 
W.A. Sandoval, \& I. Bråten (Eds.), Handbook of epistemic cognition (pp. 281-299). New York: Routledge.

Bendixen, L.D., \& Feucht, F.C. (Eds.) (2010). Personal epistemology in the classroom: Theory, research, and application. Cambridge, UK: Cambridge University Press.

Blair, J.A., \& Johnson, R.H. (1987). Argumentation as dialectical. Argumentation, 1, 41-56.

Bråten, I. (1991). Vygotsky as precursor to metacognitive theory: II. Vygotsky as metacognitivist. Scandinavian Journal of Educational Research, 35, 305-320.

Bråten, I. (2016). Epistemic cognition interventions: Issues, challenges, and directions. In J.A. Greene, W.A. Sandoval, \& I. Bråten (Eds.), Handbook of epistemic cognition (pp. 360371). New York: Routledge.

Bråten, I., \& Braasch, J.L.G. (2017). Key issues in research on students' critical reading and learning in the 21st century information society. In C. Ng \& B. Bartlett (Eds.), Improving reading in the 21st century: International research and innovations. Singapore: Springer.

Bråten, I., Strøms $\varnothing$, H.I., \& Samuelstuen, M.S. (2008). Are sophisticated students always better? The role of topic-specific personal epistemology in the understanding of multiple expository texts. Contemporary Educational Psychology, 33, 814-840.

Britt, M.A., Richter, T., \& Rouet, J.F. (2014). Scientific literacy: The role of goal-directed reading and evaluation in understanding scientific information. Educational Psychologist, $49,104-122$.

Britt, M.A., Rouet, J.F., \& Braasch, J.L.G. (2013). Documents experienced as entities: Extending the situation model theory of comprehension. In M.A. Britt, S.R. Goldman, \& J.F. Rouet (Eds.), Reading from words to multiple texts (pp. 160-179). New York: Routledge.

Brownlee, J.M., Edwards, A., Berthelsen, D.C., \& Boulton-Lewis, G.M. (2011). Self-authorship 
in child care student teachers: Is there a link between beliefs and practice? In J.

Brownlee, G. Schraw, \& D. Berthelsen (Eds.), Personal epistemology and teacher education (pp. 68-83). New York: Routledge.

Brownlee, J., Schraw, G., \& Berthelsen, D.C. (Eds.) (2011). Personal epistemology and teacher education. New York: Routledge.

Buehl, M.M., Alexander, P.A., \& Murphy, P.K. (2002). Beliefs about schooled knowledge: Domain specific or domain general? Contemporary Educational Psychology, 27, 415449.

Buehl, M.M., \& Beck, J.S. (2015). The relationship between teachers' beliefs and teachers' practices. In H. Fives \& M.G. Gill (Eds.), International handbook of research on teachers' beliefs (pp. 66-84). New York: Routledge.

Buehl, M.M., \& Fives, H. (2016). The role of epistemic cognition in teacher learning and praxis. In J.A. Greene, W.A. Sandoval, \& I. Bråten (Eds.), Handbook of epistemic cognition (pp. 247-264). New York: Routledge.

Chinn, C.A., Buckland, L.A., \& Samarapungavan, A.L.A. (2011). Expanding the dimensions of epistemic cognition: Arguments from philosophy and psychology. Educational Psychologist, 46, 141-167.

Chinn, C.A., \& Rinehart, R.W. (2016). Epistemic cognition and philosophy: Developing a new framework for epistemic cognition. In J.A. Greene, W.A. Sandoval, \& I. Bråten (Eds.), Handbook of epistemic cognition (pp. 460-478). New York: Routledge.

Chinn, C.A., Rinehart, R.W., \& Buckland, L.A. (2014). Epistemic cognition and evaluating information: Applying the AIR model of epistemic cognition. In D.N. Rapp \& J.L.G. Braasch (Eds.), Processing inaccurate information: Theoretical and applied perspectives 
from cognitive science and the educational sciences (pp. 425-453). Cambridge, MA: The MIT Press.

Council of Chief State School Officers (CCSSO). (2010). Common core state standards. Washington, DC: National Governors Association Center for Best Practices, Council of Chief State School Officers.

Creswell, J.W., \& Plano Clark, V.L. (2007). Designing and conducting mixed methods research. Thousand Oaks, CA: Sage.

Cyprus Advanced Study Colloquium (ASC) (2015, August). Changing personal epistemologies in teaching and teacher education: A focus on reflection and reflexivity. The EARLI Advanced Study Colloquium, Limmasol, Cyprus.

Dewey, J. (1933). How we think: A restatement of the relations of reflective thinking to the educative process. Lexington, MA: Heath.

Duffy, M.C., Muis, K.R., \& Foy, M.J. (2016). Examining relations between constructivist pedagogy and pre-service teachers' epistemic and learning beliefs. In G. Schraw, J. Lunn Brownlee, L. Olafson \& M. Vanderveldt (Eds.), Teachers' personal epistemologies: Evolving models for transforming practice. Charlotte, NC: Information Age.

Elmore, R.F. (2002). Bridging the gap between standards and achievement: The imperative for professional development in education. Washington, DC: Albert Shanker Institute.

Felton, M., Crowell, A., \& Liu, T. (2015). Arguing to agree: Mitigating my-side bias through consensus-seeking dialogue. Written Communication, 32, 317-331.

Ferguson, L.E., \& Bråten, I. (2013). Student profiles of knowledge and epistemic beliefs: 
Changes and relations to multiple-text comprehension. Learning and Instruction, 25, 4961.

Feucht, F.C. (2010). Epistemic climate in elementary classrooms. In L.D. Bendixen and F.C. Feucht (Eds.), Personal epistemology in the classroom: Theory, research, and implications for practice (pp. 55-93). Cambridge, UK: Cambridge University Press.

Feucht, F.C. (2011). The epistemic underpinnings of Mrs. M's reading lesson on drawing conclusions: A classroom-based research study. In J. Brownlee, G. Schraw, \& D. Berthelsen (Eds.), Personal epistemology and teacher education (pp. 227-245). Cambridge, UK: Cambridge University Press.

Fives, H. , Barnes, N., Buehl, M.M. , Mascadri, J., \& Ziegler, N. (this issue). Teachers' epistemic cognition in classroom assessment.

Gardner, S.T. (1996). Inquiry is no mere conversation (or discussion or dialogue): Facilitation of inquiry is hard work! Analytic Teaching, 16, 102-111.

Gardner, S.T. (2015). Commentary on "Inquiry is no mere conversation". Journal of Philosophy in Schools, 2, 71-74.

Gill, M.G., Ashton, P.T., \& Algina, J. (2004). Changing preservice teachers' epistemological beliefs about teaching and learning in mathematics: An intervention study. Contemporary Educational Psychology, 29, 164-185.

Gholami, K. (in press). Understanding the epistemic nature of teachers' reasoning behind their practices from an Aristotelian perspective. In G. Schraw, J. Lunn Brownlee, L. Olafson, \& M. Vanderveldt (Eds.), Teachers' personal epistemologies: Evolving models for transforming practice. Charlotte, NC: Information Age. 
Goldenberg, C., \& Gallimore, R. (1991). Changing teaching takes more than a one-shot workshop. Educational Leadership, 49, 69-72.

Goldman, S.R., Britt, M.A., Brown, W., Cribb, G., George, M., Greenleaf, C., ... Project READI (2016). Disciplinary literacies and learning to read for understanding: A conceptual framework for disciplinary literacy. Educational Psychologist, 51, 219-246.

Goldman, S.R., \& Scardamalia, M. (2013). Managing, understanding, applying, and creating knowledge in the information age: Next generation challenges and opportunities. Cognition and Instruction, 31, 255-269.

Greene, J.A., Sandoval, W.A., \& Bråten, I. (Eds.) (2016). Handbook of epistemic cognition. New York: Routledge.

Greene, J.A., \& Yu, S.B. (2016). Educating critical thinkers: The role of epistemic cognition. Policy Insights from the Behavioral and Brain Sciences, 3, 45-53.

Gregory, M. (2006). Normative dialogue types in Philosophy for Children. Gifted Education International, 22, 160-171.

Hammer, D., \& Schifter, D. (2001). Practices of inquiry in teaching and research. Cognition and Instruction, 19, 441-478.

Hennessy, S., Mercer, N., \& Warwick, P. (2011). A dialogic inquiry approach to working with teachers in developing classroom dialogue. Teachers College Record, 113, 1906-1959.

Herrenkohl, L.R., \& Cornelius, L. (2013). Investigating elementary students' scientific and historical argumentation. Journal of the Learning Sciences, 22, 413-461.

Hofer, B.K., \& Pintrich, P.R. (1997). The development of epistemological theories: Beliefs about knowledge and knowing and their relation to learning. Review of Educational Research, $67,88-140$. 
Hofer, B.K., \& Sinatra, G.M. (2010). Epistemology, metacognition, and self-regulation: Musings on an emerging field. Metacognition and Learning, 4, 113-120.

Howe, C., \& Abedin, M. (2013). Classroom dialogue: A systematic review across four decades of research. Cambridge Journal of Education, 43, 325-356.

Howe, C., McWilliam, D., \& Cross, G. (2005). Chance favours only the prepared mind: Incubation and the delayed effects of peer collaboration. British Journal of Psychology, 96, 67-93.

Juzwik, M. M., Sherry, M. B., Caughlan, S., Heintz, A., \& Borsheim-Black, C. (2012). Supporting dialogically organized instruction in an English teacher preparation program: Video-based, web 2.0-mediated response and revision pedagogy. Teachers College Record, 114, 1-42.

Kang, N. (2008). Learning to teach science: Personal epistemologies, teaching goals, and practices of teaching. Teaching and Teacher Education, 22, 478-498.

Kazemi, E., Ghousseini, H., Cunard, A., \& Turrou, A.C. (2015). Getting inside rehearsals. Journal of Teacher Education, 67, 18-31.

Khishfe, R., \& Abd-El-Khalick, F. (2002). Influence of explicit and reflective versus implicit inquiry-oriented instruction on sixth graders' views of nature of science. Journal of Research in Science Teaching, 39, 551-578.

King, P.M., \& Kitchener, K.S. (1994). Developing reflective judgment: Understanding and promoting intellectual growth and critical thinking in adolescents and adults. San Francisco: Jossey-Bass. 
King, P.M., \& Kitchener, K.S. (2004). Reflective judgment: Theory and research on the development of epistemic assumptions through adulthood. Educational Psychologist, 39, $5-18$.

Kienhues, D., Bromme, R., \& Stahl, E. (2008). Changing epistemological beliefs: The unexpected impact of a shor-term intervention. British Journal of Educational Psychology, 78, 545-565.

Kucan, L. (2007). Insights from teachers who analyzed transcripts of their own classroom discussions. The Reading Teacher, 61, 228-236.

Kuhn, D. (2015). Thinking together and alone. Educational Researcher, 44, 46-53.

Kuhn, D., \& Crowell, A. (2011). Dialogic argumentation as a vehicle for developing young adolescents' thinking. Psychological Science, 22, 545-552.

Kyriacou, C., \& Issitt, J. (2008). What characterizes effective teacher-pupil dialogue to promote conceptual understanding in mathematics lessons in England in Key Stages 2 and 3? (EPPI-Centre Report no. 1604R). Retrieved from: http://webarchive.nationalarchives.gov.uk/20130401151715/http://www.education.gov.u k/publications/eOrderingDownload/DCSF-EPPI-02-08FR.pdf

Lampert, M., Franke, M.L., Kazemi, E., Ghousseini, H., Turrou, A.C., Beasley, H., . . Crowe, K. (2013). Keeping it complex. Journal of Teacher Education, 64, 226-243.

Lederman, N.G. (1999). Teachers' understanding of the nature of science and classroom practice: Factors that facilitate or impede the relationship. Journal of Research in Science Teaching, 36, 916-929.

Leu, D.J., Kinzer, C.K., Coiro, J., Castek, J., \& Henry, L.A. (2013). New literacies: A dual-level theory of the changing nature of literacy, instruction, and assessment. In D.E. Alvermann, 
N.J. Unrau, \& R.B. Ruddell (Eds.), Theoretical models and processes of reading (6th ed., pp. 1150-1181). Newark, DE: International Reading Association.

Levitt, K.E. (2001). An analysis of elementary teachers' beliefs regarding the teaching and learning of science. Science Education, 86, 1-22.

Lim, C.P., \& Chai, C.S. (2008). Teachers' pedagogical beliefs and their planning and conduct of computer-mediated classroom lessons. British Journal of Educational Technology, 39, 807-828.

Liu, S.H. (2011). Factors related to pedagogical beliefs of teachers and technology integration. Computers and Education, 56, 1012-1022.

Lunn Brownlee, J., Ferguson, L.E., \& Ryan, M. (this issue). Changing epistemic cognition in the context of teaching and teacher education: A focus on reflection and reflexivity.

Lunn Brownlee, J., \& Schraw, G. (in press). Reflection and reflexivity: A focus on higher order thinking in teachers' personal epistemologies. In G. Schraw, J. Lunn Brownlee, L. Olafson, \& M. Vanderveldt (Eds.), Teachers' personal epistemologies: Evolving models for transforming practice. Charlotte, NC: Information Age.

Lunn Brownlee, J., \& Schraw, G., Walker, S., \& Ryan, M. (2016). Changes in preservice teachers' personal epistemologies. In J.A. Greene, W.A. Sandoval, \& I. Bråten (Eds.), Handbook of epistemic cognition (pp. 300-317). New York: Routledge.

Maggioni, L., \& Parkinson, M.M. (2008). The role of teacher epistemic cognition, epistemic beliefs, and calibration in instruction. Educational Psychology Review, 20, 445-461.

Mason, L. (2016). Psychological perspectives on measuring epistemic cognition. In J.A. Greene, W.A. Sandoval, \& I. Bråten (Eds.), Handbook of epistemic cognition (pp. 375-391). New York: Routledge. 
Mercer, N., Wegerif, R., \& Dawes, L. (1999). Children's talk and the development of reasoning in the classroom. British Educational Research Journal, 25, 95-111.

Metz, K.E. (2011). Disentangling robust developmental constraints from the instructionally mutable: Young children's epistemic reasoning about a study of their own design. Journal of the Learning Sciences, 20, 50-110.

Michaels, S., \& O’Connor, C. (2015). Conceptualizing talk moves as tools: Professional development approaches for academically productive discussion. In L.B. Resnick, C.S.C. Asterhan, \& S.N. Clarke (Eds.), Socializing Intelligence through talk and dialogue (pp. 347-362). Washington DC: American Educational Research Association.

Michaels, S., O’Connor, M.C., Hall, M.W., \& Resnick, L.B. (2002). Accountable talk: Classroom conversation that works (3 CD-ROM set). Pittsburgh, PA: University of Pittsburgh.

Muis, K., \& Duffy, M. (2013). Epistemic climate and epistemic change: Instruction designed to change students' beliefs, learning strategies and improve achievement. Journal of Educational Psychology, 105, 213-231.

Muis, K.R., \& Foy, M.J. (2010). The effects of teachers' beliefs on elementary students' beliefs, motivation, and achievement in mathematics. In L.D. Bendixen \& F.C. Feucht (Eds.), Personal epistemology in the classroom: Theory, research, and implications for practice (pp. 435-469). Cambridge, UK: Cambridge University Press.

Muis, K.R., Trevors, G., \& Chevrier, M. (2016). Epistemic climate for epistemic change. In J.A. Greene, W.A. Sandoval, \& I. Bråten (Eds.), Handbook of epistemic cognition (pp. 331359). New York: Routledge.

Murphy, P.K., Firetto, C.M., Wei, L., Li, M., \& Croninger, R.M.V. (2016). What really works: 
Optimizing discussions to promote comprehension and critical-analytic thinking. Policy Insights from the Behavioral and Brain Sciences, 3, 27-35.

Murphy, P.K., Wilkinson, I.A.G., soter, A., Hennessey, M.N., \& Alexander, J.F. (2009).

Examining the effects of classroom discussion on students' comprehension of text: A meta-analysis. Journal of Educational Psychology, 101, 740-764.

Nguyen, K., Anderson, R.C., Waggoner, M., \& Rowel, B. (2007). Using literature discussions to reason through real life dilemmas: A journey taken by one teacher and her fourth-grade students. In R. Horowitz (Ed.), Talking texts: Knowing the world through the evolution of instructional discourse (pp. 187-206). Hillsdale, NJ: Erlbaum.

Nussbaum, E.M., \& Sinatra, G.M. (2003). Argument and conceptual engagement. Contemporary Educational Psychology, 28, 384-395.

Olafson, L., \& Schraw, G. (2006). Teachers' beliefs and practices within and across domains. International Journal of Educational Research, 45, 71-84.

Olafson, L., \& Schraw, G. (2010). Beyond epistemology: Assessing teachers' epistemological and ontological worldviews. In L.D. Bendixen \& F.C. Feucht (Eds.), Personal epistemology in the classroom: Theory, research, and implications for practice (pp. 516551). Cambridge, UK: Cambridge University Press.

Organization of Economic and Cultural Development (OECD). (2013). PISA 2015 draft frameworks. Retrieved from http://www.oecd.org/pisa/pisaproducts/pisa2015draftframeworks.htm

Pajares, F. (1992). Teachers' beliefs and educational research: Cleaning up a messy construct. Review of Educational Research, 62, 307-332. 
Porsch, T., \& Bromme, R. (2011). Effects of epistemological sensitization on source choices. Instructional Science, 39, 805-819.

Rezntiskaya, A., Bråten, I., Muis, K.R. (2017, August). Professional development in dialogic teaching: The role of epistemic cognition. Paper presented at the biennial meeting of the European Association for Research on Learning and Instruction, Tampere, Finland.

Reznitskaya, A., Glina, M., Carolan, B., Michaud, O., Rogers, J., \& Sequeira, L. (2012). Examining transfer effects from dialogic discussions to new tasks and contexts. Contemporary Educational Psychology, 37, 288-306.

Reznitskaya, A., Kuo, L., Clark, A., Miller, B., Jadallah, M., Anderson, R.C., \& Nguyen-Jahiel, K. (2009). Collaborative reasoning: A dialogic approach to group discussions. Cambridge Journal of Education, 39, 29-48.

Reznitskaya, A., \& Wilkinson, I.A.G. (2015a). Dialogic teaching: Rethinking and positively transforming classroom practice. In S. Joseph (Ed.), Positive psychology in practice (2nd ed., pp. 375-399). Hoboken: NJ: Wiley.

Reznitskaya, A., \& Wilkinson, I.A.G. (2015b). Professional development in dialogic teaching: Helping teachers promote argument literacy in their classrooms. In D. Scott \& E. Hargreaves (Eds.), Sage handbook of learning (pp. 219-232). London: Sage.

Roskos, K., \& Boehlen, S. (2000). Learning the art of instructional conversation: The influence of self-assessment on teachers' instructional discourse in a reading clinic. Elementary School Journal, 100, 229-252.

Roth, G., \& Weinstock, M. (2013). Teachers' epistemological beliefs as an antecedent of autonomy-supportive teaching. Motivation and Emotion, 37, 402-412.

Ryu, S., \& Sandoval, W.A. (2012). Improvements to elementary children's epistemic 
understanding from sustained argumentation. Science Education, 96, 488-526.

Sandoval, W.A., Greene, J.A., \& Bråten, I. (2016). Understanding and promoting thinking about knowledge: Origin, issues, and future directions of research on epistemic cognition. Review of Research in Education, 40, 457-496.

Saunders, W., Goldenberg, C., \& Hamann, J. (1992). Instructional conversations beget instructional conversations. Teaching and Teacher Education, 8, 199-218.

Schraw, G. (2001). Current themes and future directions in epistemological research: A commentary. Educational Psychology Review, 13, 451-464.

Schraw, G., Lunn Brownlee, J., \& Olafson, L. (in press). Teachers' personal epistemologies: Theoretical and practical considerations. In G. Schraw, J. Lunn Brownlee, L. Olafson, \& M. VanderVeldt (Eds.), Teachers' personal epistemologies: Evolving models for transforming practice. Charlotte, NC: Information Age.

Schraw, G. \& Olafson, L. (2002). Teachers’ epistemological world views and educational practices. Issues in Education, 8, 99-148.

Slavin, R.E. (1986). Best-evidence synthesis: An alternative to meta-analytic and traditional reviews. Educational Researcher, 15, 5-11.

Snow, C., \& Hemphill, L. (in press). Learning to read while reading to learn: The central role of multiple documents in two instructional programs. In J.L.G. Braasch, I. Bråten, \& M.T. McCrudden (Eds.), Handbook of multiple source use. New York: Routledge.

Splitter, L.J., \& Sharp, A.M. (1996). The practice of philosophy in the classroom. In R.F. Reed \& A.M. Sharp (Eds.), Studies in philosophy for children: Pixie (pp. 285-314). Madrid: Ediciones De La Torre. 
Sun, J., Anderson, R.C., Lin, T.-J., \& Morris, J.A. (2015). Social and cognitive development during collaborative reasoning. In L.B. Resnick, C.S.C. Asterhan, \& S.N. Clarke (Eds.), Socializing intelligence through academic talk and dialogue (pp. 63-75). Washington, DC: American Educational Research Association.

Tabak, I., \& Weinstock, M. (2011). If there is no one right answer: The epistemological implications of classroom interactions. In J. Brownlee, G. Schraw, \& D. Berthelsen (Eds.), Personal epistemology and teacher education (pp. 180-194). New York: Routledge.

Tillema, H. (2011). Looking into mirrors: Teacher educators' dilemmas in constructing pedagogical understanding about their teaching. In J. Brownlee, G. Schraw, \& D. Berthelsen (Eds.), Personal epistemology and teacher education (pp. 40-53). New York: Routledge.

Tsai, C.C. (2006). Teachers' scientific epistemological views: The coherence with instruction and students' views. Science Education, 91, 222-243.

Trickey, S., \& Topping, K.J. (2004). Philosophy for children: A systematic review. Research Papers in Education, 19, 365-380.

Valanides, N., \& Angeli, C. (2011). Personal epistemology and ill-defined problem solving in solo and dyadic contexts. In J. Brownlee, G. Schraw, \& D. Berthelsen (Eds.), Personal epistemology and teacher education (pp. 195-209). New York: Routledge.

Vygotsky, L.S. (1978). Mind in society: The development of higher psychological processes. Cambridge, MA: Harvard University Press.

Vygotsky, L.S. (1986). Thought and language. Cambridge, MA: MIT Press. 
Walton, D. (1990). What is reasoning? What is an argument? Journal of Philosophy, 87, 399419.

Walton, D. (1998). The new dialectic: Conversational contexts of argument. Toronto: University of Toronto Press.

Walton, D., \& Macagno, F. (2007). Types of dialogue, dialectical relevance and textual congruity. Anthropology \& Philosophy: International Multidisciplinary Journal, 8, 101119.

White, B.C. (2000). Pre-service teachers' epistemology viewed through perspectives on problematic classroom situations. Journal of Education for Teaching, 26, 279-306.

Wilkinson, I.A.G., Murphy, P.K., \& Binici, S. (2015). Dialogue-intensive pedagogies for promoting reading comprehension: What we know, what we need to know. In L.B. Resnick, C.S.C. Asterhan, \& S.N. Clarke (Eds.), Socializing intelligence through academic talk and dialogue (pp. 37-50). Washington, DC: American Educational Research Association.

Wilkinson, I.A.G., Reznitskaya, A., Bourdage, K., Oyler, J., Nelson, K., Glina, M., . . Kim, M.Y. (2016). Toward a more dialogic pedagogy: Changing teachers' beliefs and practices through professional development in language arts classrooms. Language \& Education, $31,65-82$.

Wilkinson, I.A.G., \& Son, E.H. (2011). A dialogic turn in research on learning and teaching to comprehend. In M.L. Kamil, P.D. Pearson, E.B. Moje, \& P.P. Afflerbach (Eds.), Handbook of reading research (Vol. IV, pp. 359-387). New York: Routledge. 
Windschitl, M. (2002). Framing constructivism in practice as the negotiation of dilemmas: An analysis of the conceptual, pedagogical, cultural, and political challenges facing teachers. Review of Educational Research, 72, 131-175.

Windschitl, M., Thompson, J., \& Braaten, M. (2008). How novice science teachers appropriate epistemic discourses around model-based inquiry for use in classrooms. Cognition and Instruction, 26, 310-378.

Wolf, M., Crosson, A., \& Resnick, L. (2006). Accountable talk in reading comprehension instruction: CSE Technical Report 670. Pittsburgh, PA: Learning and Research Development Center, University of Pittsburgh.

Woolfolk-Hoy, A., Davis, H., \& Pape, S.J. (2006). Teacher knowledge and beliefs. In P.A. Alexander \& P.H. Winne (Eds.), Handbook of educational psychology (2nd. ed., pp. 715737). New York: Routledge.

Yadav, A., Herron, M., \& Samarapungavan, A. (2011). Personal epistemology in preservice teacher education. In J. Brownlee, G. Schraw, \& D. Berthelsen (Eds.), Personal epistemology and teacher education (pp. 25-35). New York: Routledge.

Zohar, A., \& Nemet, F. (2002). Fostering students' knowledge and argumentation skills through dilemmas in human genetics. Journal of Research in Science Teaching, 39, 35-62. 